\title{
AC 2007-1476: CULTURES WITHIN CULTURES: WELCOMING OR UNWELCOMING FOR WOMEN?
}

\section{Elizabeth Godfrey, University of Auckland}

Elizabeth Godfrey is currently the Associate Dean Undergraduate at the School of Engineering at the University of Auckland after a career that has included university lecturing, teaching and ten years as an advocate for Women in Engineering. Her research interests have focussed on the Culture of Engineering Education and Gender but new research interests are opening up in the First Year Experience, Engineering Cultures and the evaluation of learning outcomes. 


\title{
Cultures within cultures: Welcoming or unwelcoming for women?
}

\begin{abstract}
A cultural analysis of engineering education, using an interpretive case study methodology at a multidisciplinary engineering institution, exposed disciplinary subcultures or "cultures within cultures" some of which appeared more welcoming of women's participation than others. Cultural differences were noted between the engineering disciplines not only at the level of social behaviors and relationships, but also at the level of tacitly known and understood ways of valuing knowledge, teaching, and learning. A local plateauing of overall female participation at approximately $20 \%$ masked persistent differences in female participation by discipline, reflecting international trends. This paper suggests that a study of these disciplinary subcultures may clarify the persistence of this differential participation, and lead to the formulation of new approaches to increasing women's participation in engineering education.
\end{abstract}

\section{Introduction}

Is it a self-fulfilling prophecy that engineering disciplines with more women develop cultures that attract more women? Can, and should, this pattern be disrupted?

These questions arose in the context of a cultural analysis of engineering education, which primarily sought to explore the interaction of the participation of women (the feminine) with a culture which has often been named as masculine (i.e. not feminine). The masculine nature of the culture of engineering education has been named as a major inhibiting factor to the increased participation of women ${ }^{1,2}$, with masculine values, norms and assumptions identified not only at the level of social interaction and discourse, but at the deeper levels of knowledge generation and transmission ${ }^{2,3,4,5}$.

The publication of the 1996 Australian Review of Engineering Education ${ }^{6}$ entitled Changing the Culture called for "a culture change in engineering education, ultimately to extend throughout the profession" and explicitly noted that this transformation had the potential to attract more women to the profession. The Australian review echoed discussions occurring simultaneously in the UK, USA and Canada. Increasingly in the last ten years the term "culture" has entered the engineering education discourse and it seems implicitly understood that engineering education has a distinctive culture, recognizable to all its practitioners. Outside of the gender literature however, little theorising about the nature of the engineering culture can be found, and one of the drivers for the investigation from which this paper is drawn was to develop a conceptual framework for the engineering education culture that would be accessible to engineering educators. The resulting framework was reported on at the 2003 conference $^{7}$ and although it will inform this paper it will, of necessity, not be fully described at this time.

A second driver for the investigation, was the apparent assumption of a unified homogeneous culture with a significant lack of research, even within the gender literature, into national, institutional and discipline-specific subcultures within engineering education.

Over the last ten years, the reporting of a plateauing of female participation at near $20 \%$ in the $\mathrm{US}^{8}$ and other countries, has masked the continuing differential participation between the 
engineering disciplines and even between institutions. It is suggested that a connection exists between local versions of the engineering education culture and this differential participation.

In Australia, both Byrne ${ }^{9}$, and later Cobbin ${ }^{10}$ observed that some institutions persistently attracted higher female participation than others. This higher participation often appeared unrelated to specific promotional initiatives. Illustrating this trend, Cobbin's data showed participation in a single discipline such as Civil Engineering ranging from 7-27\% across different institutions in Australia in 1993.

Cobbin ${ }^{10}$ suggested that women's representation in the various engineering fields of study tended to be:

- higher in relatively small fields of study rather than the large mainstream groupings, therefore providing fewer graduates in spite of increasing representation;

- higher at the established universities or campuses compared with newer institutions where comparable courses were available;

- lower for courses perceived as less prestigious ( i.e. lower entry requirements) in the same discipline area;

- lower in sub-degree courses than degree courses (in the same discipline area);

- lower in computer oriented engineering courses with a hard core computer programming emphasis;

- higher in courses with chemical and life science orientations (e.g. chemical, environmental);

- higher in some double degrees that permit a broadening of studies (i.e. arts or science) rather than more of the same thing (i.e. computer science).

A project report commissioned by the European Union ${ }^{11}$ similarly commented that national, institutional and discipline specific differences appeared highly likely to provide a complex picture, where the culture would be influenced by the nature and content of a discipline and how it was practised in the "real world", as well as influenced and reinforced by how staff and students played their role.

Recent participation data for the US in 2004, provided in Table 1, demonstrate that Electrical and Mechanical Engineering - which together account for approximately one-half of all degrees awarded in Engineering - have a collective percentage of female degree earners of just 14\%, while all remaining Engineering disciplines - account for the remaining half of degrees issued in Engineering - having double that percentage at $28 \%$.

Table 1: Earned Bachelors Degree by Gender $2004^{12}$

\begin{tabular}{|l|r|r|r|r|c|}
\hline \multicolumn{1}{|c|}{ Academic Discipline/Field } & \multicolumn{1}{c|}{ Both Genders } & \multicolumn{1}{c|}{ Female } & \% Female & Male & \% Male \\
\hline All Academic Disciplines & $1,407,009$ & 810,817 & $58 \%$ & 596,192 & $42 \%$ \\
\hline All Science \& Eng Disciplines** & 454,978 & 229,412 & $50 \%$ & 225,566 & $50 \%$ \\
\hline Eng \& Closely Related Fields*** & 164,415 & 41,760 & $25 \%$ & 122,655 & $75 \%$ \\
\hline Chemistry & 9,305 & 4,755 & $51 \%$ & 4,550 & $49 \%$ \\
\hline Physics & 4,156 & 908 & $22 \%$ & 3,248 & $78 \%$ \\
\hline Math \& Statistics & 13,755 & 6,318 & $46 \%$ & 7,437 & $54 \%$ \\
\hline Computer Science & 57,405 & 14,406 & $25 \%$ & 42,999 & $75 \%$ \\
\hline Engineering Technology & 15,119 & 2,116 & $14 \%$ & 13,003 & $86 \%$ \\
\hline
\end{tabular}




\begin{tabular}{|l|r|r|r|r|l|}
\hline Engineering & 64,675 & 13,257 & $20 \%$ & 51,418 & $80 \%$ \\
\hline Chemical Engineering & 5,185 & 1,833 & $35 \%$ & 3,352 & $65 \%$ \\
\hline Civil Engineering & 9,399 & 2,279 & $24 \%$ & 7,120 & $76 \%$ \\
\hline Electrical Engineering & 21,342 & 3,032 & $14 \%$ & 18,310 & $86 \%$ \\
\hline Mechanical Engineering & 14,368 & 1,952 & $14 \%$ & 12,416 & $86 \%$ \\
\hline All Other Eng Fields & 14,381 & 4,161 & $29 \%$ & 10,220 & $71 \%$ \\
\hline
\end{tabular}

Time series data provided in Figure 1, graphically illustrate that whereas Chemical, Civil and all other engineering fields continued to rise in female participation until relatively recently, Electrical and Mechanical participation has barely risen in the last twenty years.

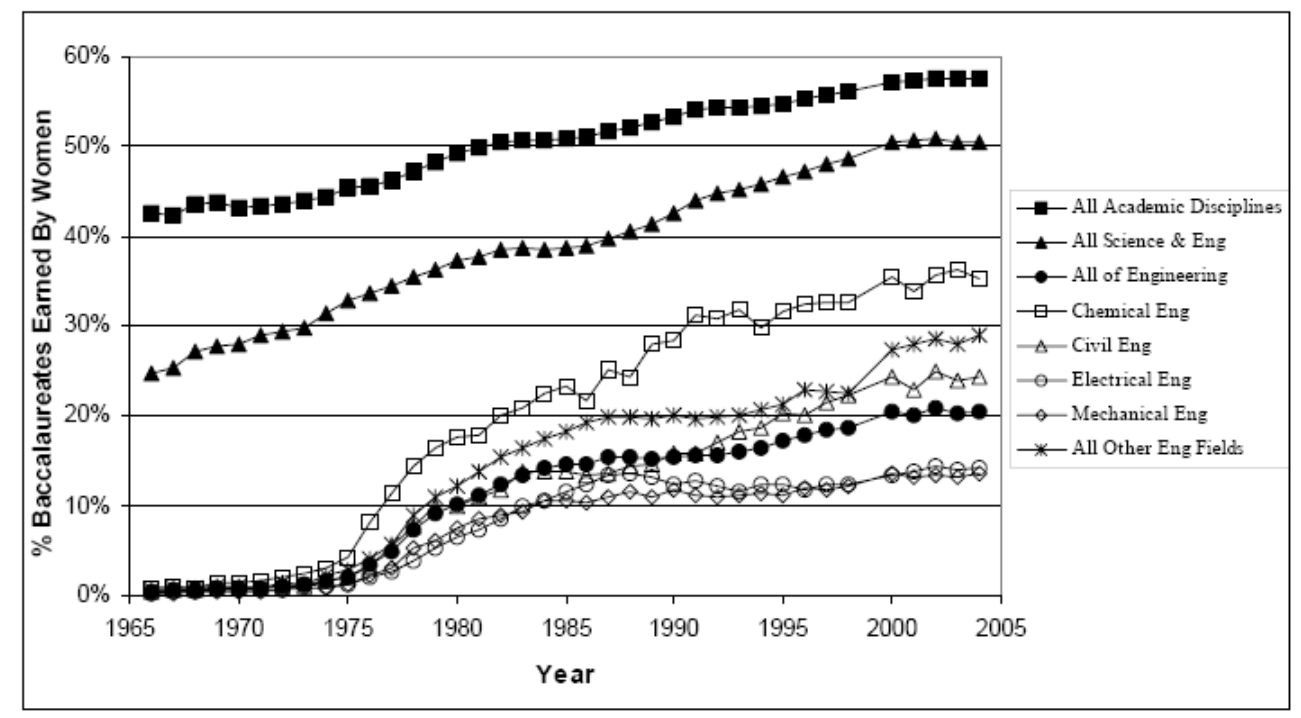

Figure 1. Percentage Of US Female Degree Earners In Engineering And Its Sub-Disciplines $-1966-2004^{12}$

The repetition of these trends over time and location suggest that; if it is accepted that a relationship exists between the culture of engineering education and the under-representation of women, then it is reasonable to presume that studies of discipline specific subcultures will provide insights into the persistence of the differences in female participation. Given that the operating unit for most staff and students in engineering, for at least three years of their academic life, is at the close-knit departmental level, it is suggested that the almost complete lack of theorising about the formation of disciplinary subcultures needs addressing.

Those subcultures (institutional or discipline specific) with a high participation of women that appear to provide an inclusive cultural experience for women students and others of minority groups may provide the basis of appropriate cultural change strategies. It seems likely that they have developed norms, values and beliefs that have "opened" up the culture of engineering education to value and welcome the participation of women. Similarly, an investigation of the features, both academic and social, of those disciplines which remain obdurately low in women's participation may provide revealing information about potential barriers. 


\section{Context of the study.}

The findings presented in this paper form part of a cultural analysis of engineering education and the interaction of that culture on the participation of women, as exemplified in a multidisciplinary School of Engineering, at the U of A, a large, well established New Zealand university.

As with most institutions, this School of Engineering has some unique features. Analysis of the history of the School demonstrate that these include:

- historically a tradition of unity between departments

- all departments and facilities located, until 2004, in one building on the main campus

- a four year professional course with applications exceeding places necessitating selection on academic criteria at first year level

- a high proportion of students( approximately 50\% at first year level), predominantly from Asia who have lived in NZ less than 8 years.

- The size of the undergraduate student body at U of A has grown from 1500 to 2000 over the last ten years

- International research ranking of number one in New Zealand

The institution has been committed since 1989 to increasing the proportion of female students and staff with long term support of a Women in Engineering co-ordinator and other initiatives aimed at increasing access and retention. Even more critical, the management team policy does not condone or tolerate, behavior or events that might be offensive to women or other minority groups. After initially fast growth in overall female participation from less than $10 \%$ in 1989 by 1996 , when this study commenced, participation was slowing and had almost reached $20 \%$. For more than 8 years now overall female undergraduate participation has been $20 \pm 1 \%$ mimicking international trends. This level of participation is the highest in New Zealand, and as high as any university in Australia, with retention to graduation higher for women than men, suggesting that this institution could be viewed as providing a welcoming and supportive culture for women. It is recognised however that, whilst women are welcomed, there is little critique or understanding of the gendered nature of the culture and its impact on women.

Table 2. Female participation by percentage from 1998-2006 by Engineering sub-discipline at UofA.

\begin{tabular}{|l|r|r|r|r|r|r|r|r|r|r|}
\hline Year & $\mathbf{1 9 9 8}$ & $\mathbf{1 9 9 9}$ & $\mathbf{2 0 0 0}$ & $\mathbf{2 0 0 1}$ & $\mathbf{2 0 0 2}$ & $\mathbf{2 0 0 3}$ & $\mathbf{2 0 0 4}$ & $\mathbf{2 0 0 5}$ & $\mathbf{2 0 0 6}$ & Average \\
\hline General & & & & 20.9 & 21.8 & 20.2 & 20.4 & 19.7 & 21 & $\mathbf{2 0 . 7}$ \\
\hline Biomedical & & & & & 45 & 57.1 & 50.8 & 47.8 & 43 & $\mathbf{4 8 . 7}$ \\
\hline Chem' \& Materials & 37.6 & 37 & 38 & 33.3 & 34.9 & 28.4 & 38.1 & 41.6 & 36.4 & $\mathbf{3 6 . 1}$ \\
\hline Civil & 24.4 & 21.6 & 20.5 & 16.6 & 15.9 & 18.4 & 17.1 & 17 & 18.8 & $\mathbf{1 8 . 9}$ \\
\hline Computer Systems & & 10.9 & 13.8 & 13.8 & 13.4 & 14.6 & 18.7 & 14.8 & 11.6 & $\mathbf{1 4 . 0}$ \\
\hline Electrical\&Electronic & 11.7 & 12.5 & 14.2 & 17.6 & 15.8 & 13.3 & 16.8 & 21.8 & 19.2 & $\mathbf{1 5 . 9}$ \\
\hline Engin'g Science & 25 & 36.1 & 45 & 43.1 & 40.8 & 50 & 25.4 & 25.4 & 28 & $\mathbf{3 5 . 4}$ \\
\hline Environmental & 40 & 42.9 & 41.5 & 40.5 & 47.6 & 51.1 & 58.3 & 50 & 62.5 & $\mathbf{4 8 . 3}$ \\
\hline Mechanical & 10.9 & 11 & 11.1 & 11.7 & 11 & 11.9 & 8.4 & 8.5 & 10.8 & $\mathbf{1 0 . 6}$ \\
\hline Mechatronics & & & & & 13.5 & 9.3 & 9.4 & 8.9 & 8.63 & $\mathbf{9 . 9}$ \\
\hline Software & & & & 21.1 & 20.1 & 17.9 & 20.4 & 16.3 & 15 & $\mathbf{1 8 . 5}$ \\
\hline Overall & $\mathbf{2 0 . 7}$ & $\mathbf{1 9 . 7}$ & $\mathbf{2 0 . 8}$ & $\mathbf{2 0 . 6}$ & $\mathbf{2 0 . 2}$ & $\mathbf{1 9 . 3}$ & $\mathbf{2 0 . 2}$ & $\mathbf{2 0}$ & $\mathbf{1 9 . 7}$ & $\mathbf{2 0 . 1}$ \\
\hline
\end{tabular}


As indicated in Table 2, a time series of disciplinary female participation at $\mathrm{U}$ of A reflects international patterns of subdisciplinary participation.

In the case study institution, Civil, Mechanical, and Electrical Engineering were the most traditional and well-established disciplines, with international as well as national professional associations. That background appeared to be linked to entrenched beliefs and assumptions about curriculum content, pedagogies and professional issues appropriate to each discipline. Chemical Engineering was newer (first taught as a separate discipline at the U of A in 1967) but was also an internationally recognised discipline. The Department of Engineering Science was a younger (approximately 25 years old) and less traditional discipline. Biomedical Engineering, with a first intake in 2002, was an offshoot of Engineering Science with a focus on mathematical and computer modelling of biological systems. The younger disciplines of Environmental Engineering, Computer Systems Engineering, Software and Mechatronics were offshoots of well-established departments (Civil, Electrical and Mechanical) and did not appear to have developed separate cultural identities at the time of this study (1996-2003) and will be discussed as part of their "home" department.

No staff or student group within an institution is a homogeneous group. It is postulated that subcultures having shared values and understandings exist and several classifications were identified including: new immigrant NESB students who formed common-language based groups, the "blokes"- those who continue the legend of "hard partying and drinking" and the "nerds" - those who focus entirely on academic grades and seem wedded to their computers.

The prolonged close proximity within departments and disciplines induced by a class staying together for three of the four years of the degree with prescribed curricula and shared teaching and research, led to recognition by both staff and students of generalisations and perceived stereotypes, epitomised by the comment

"We are all engineers but the departments are like different tribes"

\section{Methodology}

Those familiar with cultural theory will recognise that it is the shared values and cultural norms underpinning observable behaviors and practices which are the essence of a culture. Any analysis of a culture seeks to get beneath the observable to the shared understandings that members have around those behaviors and practices, and if possible to the core of unconsciously held beliefs and assumptions. Schein's ${ }^{14}$ well known cultural framework, suggested as a very accessible model, was used as a starting point for this analysis.

Qualitative methodologies, in particular extensive ethnographic research, were identified by Schein ${ }^{14}$ as necessary to understand the deepest, unconscious levels of culture and processes of enculturation. An interpretive (theory building) case study methodology ${ }^{15}$ was therefore chosen, including, although not exclusively, ethnographic methods within an overarching interpretivist research paradigm. Multiple methods of data collection, which supplemented several years of participant observation and interviews with a range of staff and students (both male and female), questionnaires, focus groups, workshops, statistics and a wide range of documents and publications, evidenced the used of methodological, data and time triangulation contributing to the credibility of subsequent theory development. These methods were seen to be well suited within a cultural study which needed to answer questions like "what is going on here?" and to decipher "how things are" and "how did they get to be that way?". 
The method of data analysis and model formation is described more fully in the 2003 conference paper ${ }^{7}$. In summary:

The first level of analysis was the identification and coding of observable and tangible manifestations of the culture from the raw data, grouped as Artefacts, Behaviors, and Practices.

The second level of the analysis was the interpretation of this data to reveal cultural values and norms which were shared and understood by members of the culture, albeit often tacitly rather than explicitly. This level of analysis was particularly revealing of enculturation processes. Tonso ${ }^{16}$ had described engineering education as "enculturation into a wellestablished system of practices, meanings and beliefs" as students "learn what it means to be an engineer" (p.218) and in this study a wealth of examples demonstrated how students interpreted day to day practices and behaviors to determine what was valued and rewarded by academic and social success.

The third level of analysis was based on the premise of the suggested model that the observable and tangible manifestations, and cultural norms identified in the first two levels of analysis had developed from shared beliefs and assumptions which had formed over time as engineering educators and students sought to find their personal and collective answers to issues which Schein ${ }^{14}$ had named "issues of external adaptation and internal integration". These issues, for engineering education were seen as focused around the following questions:

What kinds of knowledge were valued? What was seen as truth? Was there a prevalent "way of thinking?"

Were there attributes and qualities inherent in being "an engineer"? Who fitted in and was successful?

What was the primary task - how was it to be accomplished - was there a "right" way to teach/learn?

What was the relationship of the culture of engineering to the rest of the university and academia in general, the profession and community?

What was considered the "right" way for people in this culture to relate to one another? Was it seen as desirable or necessary to have homogeneity or diversity in the members of the culture? How was difference accepted?

At this third level of analysis therefore, using these questions as a base, shared beliefs and assumptions were distilled from the values and norms identified at the second level of analysis and grouped into six dimensions. These were named as:

- The Engineering Way of Thinking

- The Engineering Identity

- The Engineering Way of Doing

- Relationship to the Environment

- Relationships

- Homogeneity

It was recognised that some features of the culture at the case study institution may have been unique, such as the tradition and valuing of integration between the disciplines, and the School of Engineering's sense of identity and isolation from the wider university, but many 
of the beliefs and assumptions identified in these cultural dimensions appeared to be the source of practices and behaviors commonly identified in the international research literature.

For each of these cultural dimensions, there were commonalities across all the engineering disciplines, but as will be shown in the next section, differing and quite persistent values, cultural norms and assumptions had developed within the disciplines. In the following section relevant aspects of the disciplinary subcultures at the case study institution will be analysed to throw light on the source of cultural behaviors and practices which are associated with higher and lower levels of participation and performance of women.

\section{Results}

Disciplinary participation starts with disciplinary choice, and the question does need to be asked; is culture an inhibiting factor in discipline choice? Engineering students at $U$ of A made their choice of discipline after a common first year with exposure to each of the potential choices via first year lecturers and courses, explicit career-related seminars and displays. Interviewed students were questioned on their reasons for their disciplinary choice but it would be difficult to find evidence that students had a conscious awareness at that time of cultural differences. There was evidence to suggest that all female students who were attracted to engineering had above average confidence and ability in mathematics and science, but having made the decision to study engineering, their choice of discipline sometimes appeared to have been fairly random and often swayed by a personable lecturer, perceptions of career potential or even a process of elimination. Comments such as these were typical:

$$
\begin{aligned}
& \text {...it was sort of like - like I wasn't looking towards mechanical engineering from the beginning, it } \\
& \text { was more like I didn't want the other options... }
\end{aligned}
$$

I thought I'll take Engineering to prove to myself that I can do something that looks quite hard in the first place, and Engineering Science had lots of maths Colleen

The reason I chose engineering was because I knew there were a lot of jobs available in New Zealand and the honest truth is that I knew there were pretty good jobs available for the electrical engineers and I knew I could make a reasonable career out of it.

Geetha

Female students rarely spoke of entering engineering with a commitment or passion for one particular discipline. Not all male students were as committed as one student who commented "I was born to be an engineer" but it was not uncommon for male students to enter with specific aims in mind:

I am another step towards fulfilling my dream. Imagine a world of robots, cyborgs, and humans, living together.

Simon

I love aesthetics, and buildings and things and ...I wanted to understand the underlying form of everything, in terms of the forces, and the physics, not just how it looks

Angus

The first round of interviews with the graduating class of 1997 highlighted markedly different experiences and outcomes for female students. Academic differences such as what knowledge was valued, the strength of focus on mathematical solutions and the "provable", the extent to which social and environmental issues were viewed as "real" engineering and other such pedagogical issues were observed. In addition, measurable factors such as class size and the homogeneity of the class in terms of age, gender and ethnicity, as well as intangible factors such as the nature of relationships, had the potential to impact on the culture that developed within a discipline. 
Referring back to the data in Table 2, the disciplines Biomedical Engineering, Chemical and Materials Engineering, Environmental Engineering and Engineering Science consistently had female participation figures $(>30 \%)$ at levels that Byrne ${ }^{9}$ deemed "sex normal" for both sexes and might therefore be considered sex-neutral. The level of participation in these disciplines, combined with observation and interview data, suggested that they might have some features of welcoming, inclusive disciplinary cultures. The average class size for each of these disciplines was small with a maximum of $40(\mathrm{C} \& \mathrm{M})$ and a minimum of 10-15 (Env).

The participation in Civil Engineering, on Byrne's ${ }^{9}$ classification, could be seen as "untypical but sex-normal" (16-29\%) for the minority (female) sex. Although participation has risen in Electrical and Software in the last few years, at the time of the study 1996 - 2003, the level of participation in Electrical and Mechanical Engineering was closer to "abnormal" for their sex ( 9-15\%) for female students. Alongside the long-standing low levels of participation of women in Electrical and Mechanical Engineering, the data collected suggested inconsistencies in their experiences. Over the time of the study, a group (albeit a relatively small group) of competent, confident young women graduated from Mechanical Engineering. They contrasted with women from Electrical Engineering who often lacked confidence in their own ability and thought of their degree only in terms of survival. Other contradictions arose - including a perception that, within the overall masculinity of the engineering culture, a range of masculinities seemed to be evident when comparing the behaviors and practices of, for example, Civil Engineering and Electrical Engineering.

In the bigger study each of the dimensions was examined for each of the subdisciplines, but in the space available for this paper, exemplars of the shared beliefs and assumptions which are the source of behaviors and practices associated with higher and lower levels of participation and performance of women are provided for only two of the dimensions. In the following sections shared beliefs and assumptions linked with the Engineering Way of Thinking and the Engineering Identity are discussed in further detail.

\section{The Engineering Way of Thinking}

This dimension dealt with the shared beliefs and assumptions around the questions: What kinds of knowledge were valued? What was seen as truth? Was there a prevalent "way of thinking?". Many of these beliefs and assumptions were unconsciously held and taken for granted by both engineering academics and professional engineers.

Within engineering as a whole, it was identified that truth and reality were proven and described by mathematics. Mathematics was inextricably pervasive and essential as a key to access, understanding and thinking like an engineer.

Hacker $^{17}$ and Byrne ${ }^{9}$ had linked lower female participation in disciplines with a heavy content of mathematics, to masculinising of disciplines. Mathematics was an integral component across all disciplines of engineering in the way knowledge was accessed, valued and assessed, and engineering analysis and design were performed. Evidence for this study suggested however, that the role and importance of mathematics within the disciplines differed sufficiently to give rise to comments such as the following:

I started out in E\&E and I bombed, and I was advised to do Civil because it had less maths in it less maths content therefore it must be easier. I thought of Engineering. Science, but everybody thought Engineering. Science was hard because it had all that maths in it. Trish 
Trish's comment was representative of a common belief that the level and role of mathematics was one of the criteria that established status and contributed to a perception of the hard/soft positioning of a discipline. The same sort of beliefs appeared to be held around the relative hard/soft nature of courses even within a discipline:

Although we all focus on applying knowledge and use mathematics for analysis and modelling, there is definitely a difference in the department in the way we view subjects like Control, Thermo, Strength of Materials ... which require mathematical analysis and are dominated by people with mathematical strengths and the more practical ones like Management and Manufacturing - their analysis is also complex but sort of more wordy and descriptive. They don't command the same respect and aura. I would tend to send a poorer student towards the Project Management side.

MechStaff10

In the late 1990s, Electrical and Electronic Engineering was the department that might have been seen to epitomise Byrne's ${ }^{9}$ link between mathematicss and low female participation. Participation in Engineering Science, however, appeared to refute this link. Although only a small department, female participation increased through the late 1990 s to a level of $45 \%$, with women emerging as high achievers and emphatically positive about both their academic and social experiences in the discipline. Yet Engineering Science was almost totally focussed on mathematical modelling using computer simulation.

The use of mathematics in Electrical Engineering was perceived as dominated by manipulation, derivations, and proofs, rather than just application of formulae:

...like in electrical engineering you want to do something you have to do all this maths to figure out what you are going to have to do.

Richard

The vast advances in digital electronics... upped the stakes on the maths considerably ...our students always used LaPlace transforms in terms of solving circuits that have got transient behavior but the related Fourier transforms were only encountered in graduate work, now routinely used in an undergraduate course

EEStaffi

... we have gone for a system here where we think students really need to know what is going on inside and can design it. But to understand what is going on they have to do some mathematics.

EEStaff4

It was common in these courses to see pages of lecture notes without a single word of English, but combinations of mathematics, and diagrams. The language of Electrical Engineering clearly involved mathematics and visual/symbolic images, rather than words, which were seen, as indicated below, to be less efficient:

We could use words but it would take a lot of words, so in a sense we are using a type of shorthand. Graphs are a good way of showing trends, formulae show relationships, and increasingly flow diagrams to represent the logic by which you do things ... all just very efficient ways of trying to convey the interrelationships between a complex range of parameters

EEStaff1

Electrical Engineering used high order mathematics and a variety of visual images to analyse and solve complex but intangible systems requiring a high degree of abstraction. This was seen by staff as in contrast to disciplines such as Civil Engineering in which mathematics appeared to be used in more of a "plug in the formula" way.

EE is more polarizing now than any of the other disciplines in the sense that-partly the maths and the specifics of it, but also partly the development of the skills of analytical thinking that are

important and I would have thought that is not so true in Civil where the maths is a means to an end of working out what the forces and stresses and how big the beam needs to be. EEStaff4 
A number of sources indicated that mathematics and computing were dealt with differently in Engineering Science. Engineering Science, with its branches of Operations Research and Biomedical Engineering, attracted high numbers of female students for whom mathematics held no fear. Mathematics was seen by these students as the tool that opened the doors to problem solving and modelling that required innovative and quite creative thinking. The modelling of real life, identifiable problems such as tidal flows, electrical activity round the heart, and fluid flow round sails was accessed through very specialised computational mathematics techniques. These were applications seen by students as useful to people and challenging intellectually:

I always connected so much of the work going on in E. Sci back to people - the environmental fluid mechanics, the geothermal work - I wanted to do something that was about people rather than just equations on a page.

Rose

Therein, it is suggested, lay the attraction Engineering Science held for female students and others who sought a connection with the material they were studying. The application of high level mathematics appeared to be seen in Engineering Science as not only intellectually challenging, but also useful to people, whereas in Electrical Engineering the high degree of abstraction and intangibility of the outcomes appeared to mask connective links for many of the students.

Cobbin's ${ }^{10}$ statement that female participation was lower in those disciplines with a high content of "hard" core computer programming was not a systematic trend in this study. Low participation in Electrical and Computer Systems Engineering, relative to higher participation in Civil and Chemical Engineering, appeared to confirm this perception, but Software Engineering, particularly in its early years, had female participation as high as Civil Engineering. Again, however, Engineering Science, in which almost all of the high level mathematics was utilised in conjunction with computer modelling (resulting in a very high component of programming in its courses) appeared anomalous. Forces other than an attraction or repulsion to computing were clearly affecting participation in the latter discipline.

These disciplines illustrated for me that a simplistic linking of low participation with high content of mathematics and computing, particularly by authors writing from outside engineering such as Hacker ${ }^{17}$, did not take account of the role and contexts in which mathematics and computing were used. It is suggested as more helpful to look for explanations in linking concepts of separate and connected knowing ${ }^{18,19}$ with the disciplines. The much quoted Belenky et al. ${ }^{19}$ hypothesised that more women than men may be "connected knowers" (where the relationship between the self and the knowledge is important - being able to link topics to personal experience) and that more men than women operated as "separate knowers". Separate knowing, they suggested, was more like the traditional, objective, rule-seeking ways of evaluating, proving or disproving truth - reflected in most secondary and higher education curricula and teaching, particularly physics and engineering. Male students attracted to science and engineering have been identified as usually more comfortable with the disconnection between theory and context. Baxter-Magolda ${ }^{18}$ however had apprehensions with dichotomous generalisations around gendered ways of knowing and preferred to use the analogy of "prevailing winds" to explain the fluidity of patterns of knowing which were gender-related but not employed exclusively by one gender.

The focus in engineering on real life applications appeared to create openings for those who might be more comfortable with connected knowing. The goal across all disciplines was to 
put engineering content into real life contexts. Comments such as the one by MechStaff10 earlier in this section, however, with its implication that a "poor" student" was one with low ability in mathematics, matched a perception of the dominance and higher value placed, not only on courses with higher level mathematics, but on separate knowing. The more respected and "hard" engineering across all disciplines appeared to be taught in a "pretty dry manner" and was perceived by students as theory or concept oriented, accessed via mathematical tools, and not well linked to context or use. Difficulties were experienced by those students who needed to feel "connected" to the subject matter they were trying to understand:

I couldn't like Solids at all because I just can't picture stress in a beam and I can't understand, I can't really visualise it and I just yeah... and with fluids and looking at cycles in a steam plant I could see how it would be useful

Chloe

A preference for connected knowing appeared to be the explanation behind Cobbin's ${ }^{10}$ generalisation that higher female participation was observed in those disciplines which dealt with chemical and life sciences. Chemical Engineering (with its consistently higher than average female participation) and Civil Engineering both dealt with tangible outcomes that appeared to be accessible and connected universally to real life experience.

Most of us can have a reasonable discussion with a Civil about the new building being built next
door but if we get into a discussion on electromagnetic radiation or interference or whatever
because you can't actually point to it, it requires a language and a set of concepts that one can't
make that kind of constructionist leap
EEStaff1

The content of the Civil Engineering curriculum was a mix of structural design and analysis, transportation, public health and environmental management. As with any academic discipline, Civil Engineering had its own technical jargon, but the potential for "connection" with the subject matter appeared to be important for students like Trish:

Civil is more real in terms of what people experience every day-like you have pegs you can hang things on. You couldn't necessarily read an environmental mechanics exam but someone could explain it to you ... you can make connections...

Trish

The new discipline of Environmental Engineering attracted almost 50\% female participation, although the discipline never attracted large class sizes, and by 2004 it was merged back as part of the Civil Engineering Department.

Electrical Engineering, compared to other disciplines that dealt with tangible outcomes, often seemed to be concerned with less visible or accessible concepts and products. A preponderance of terms such as impedance, resistance, bandwidths and signal processing, that were accessible only to those with the same training, may have contributed to a sense of isolation and difficulty in communicating with non-electrical engineers:

She told me she chose to do a particular final year project to study how tumours can be treated by controlling the electronic field ... because it was something she could easily explain to her family and friends ... whereas if she told them "I am learning linear systems or doing Fourier analysis" their eyes glazed over and she felt like an alien

EEStaff4

Electrical has moved from dealing with physical identifiable artefacts to a more abstract realisation - intangible - still definable, measurable and quantifiable......Many of the students become detached because the connection between the subject they study and the application is being stretched...

EEStaff1

The lack of connection felt by many of the female students in Electrical Engineering, even those earning high grades, implied that this abstraction and the intangible nature of many of the "products" of electrical engineering were largely responsible for the initial lack of 
recruitment of women to this discipline and the lack of commitment evidenced even by those who completed the degree successfully.

\section{The Engineering Identity}

The dimension named as "The Engineering Identity" contained shared beliefs and assumptions around the answers to the questions: Were there attributes and qualities inherent in being "an engineer"? Who fitted in and was successful?

This study affirmed the masculinity of the understandings around what it meant to be an engineer and the gendered behavioral norms within the overall engineering education culture. Connell $^{20}$ wrote on the construction of masculinity and in particular recognised that masculinity was not a singular phenomenon and in any group some masculinities were likely to be valued more highly than others. From evidence gathered in interviews and extended observations, it was concluded that there were marked disciplinary differences in constructions of masculinity. The dominant masculinity in Civil Engineering (and to a lesser extent Mechanical Engineering), for example, was quite distinct from that found in Electrical and Electronic Engineering.

The dominant masculinity in Civil Engineering, "the good Kiwi bloke", appeared to closely match the conservative, traditional NZ masculinity described by Phillips ${ }^{21}$. The discipline had a long history of male dominance and it had only been in the last 12 years at the case study institution that female participation had risen out of the "rubric of exceptions" 9 (<9\%) or token level. It was, however, a discipline with contradictions. From time to time it provided the worst instances of sexism and male chauvinism of all the disciplines, yet the majority of female students appeared to emerge confident, articulate and connected strongly to their role as potential professional engineers.

In Civil Engineering, to be male was very much the norm, and this was apparent in the use of language, which habitually included male examples:

It really blew me away, the lecturer was a female and she was talking about management issues in Civil Engineering and she just kept saying "he, he, he..." - I mean I didn't expect it from her. Trish

Humour of the "male bonding" type was prevalent, emphasising again that being male was the norm:

Lots of sniggering, always talking about rigid members and that sort of thing ...Discipline had all these lovely words with double meanings - I didn't find it a problem ...unless they turned round and apologised...

Trish

Civil engineering students, both male and female, were always strongly represented in the Engineering Students' Society, and often took leadership roles. There seemed to be a contradiction between the image or stereotype of a Civil Engineer and the day-to-day reality as evidenced in Rebecca and Samuel's comments:

I think the key thing was that people expected it to be - so like you get a lot of pressure - you guys are Civil you' re going to be like this - the individuals probably didn't fit the stereotypes but when they got together there was a pressure to act a certain way... if you are going to be an engineer and you consider yourself a bloke already - you know the rugby drinking sort-you are not going to go off and do some sort of namby pamby thing like electrical...

Samuel 
...there is a kind of mismatch between the image and reality - image blokey macho-you will see things that reinforce that image but if you looked at the sum of all of the activity - they are not blokey macho $99 \%$ of the time, have only a few reinforcing the image - if you look at any one individual they really weren' $t$ - it was the stereotype...

Rebecca

This contradiction, between the stereotype and the day-to-day reality, appeared to provide the space for female students to be accepted and participate as members of the group. I noted over the years that female students from Civil Engineering consistently appeared to be self confident, articulate and willing to take on leadership roles:

When I look at the women in my class, they did have what I call masculine traits - sort of get in
there and do it - if they didn't like something they would say so, very blunt... Trish
Some of the girls in my class definitely identify with the bloke thing - and are more inclined to be
'one of the boys' - but that is not the whole picture. I mean the Asian women weren't like that-
they do defer to the guys more than we do, but they seem different to the girls in electrical-more
connected somehow Rebecca

Success in Civil Engineering required adaptation to the department's masculine behavioral style, which appeared to be more easily accommodated by those young women familiar with traditional New Zealand masculine behavior. The confidence with which the female students spoke out against examples of perceived gender-related or other injustices seemed to me to imply a high level of personal self confidence, but also a perception of sufficient support from staff and their peers.

Mechanical Engineering offered a similar picture, with a consistent male: female ratio of 9:1. Learning styles, humour, background, and behaviors were assumed to be those of the male students and it appeared that equity in this discipline meant accepting females who met the same criteria as males i.e. they conformed to male norms. The female students interviewed and observed over several years fitted into the prevailing culture, with little protest. One realised (on reflection after interview) that she had adapted her behavior to fit the environment:

Funny thing though... I have noticed that when I'm working in an engineering context I take on a whole different persona. It's still me... crude, blunt, intelligent, etc. but my voice seems to be lower and my stance and posture would be more masculine (I guess you can say that). I found that the attitude I present helps others to take me seriously as an engineer.

Julie

In contrast, not all the attributes and qualities inherent in being an "engineer" applied to Electrical Engineering staff and students, particularly the traditional "blokey" stereotype of the "partying, drink hard" engineering student. Ability in mathematics and, increasingly in more recent years, skills or confidence using computers and programming were generalisable attributes that were associated with staff and students in this department. The image of Electrical students as "geeks", implying a narrowly focussed, clever, but physically unprepossessing student, with an almost obsessive interest in computers, was prevalent in the perception of Electrical Engineering students by themselves and others:

By necessity, in terms of work habits you really have to be what other faculties describe as a geek

Brett

Nerdy, geeky comes with the nature of the discipline, seems more remote - so much is not able to be realised or shown in simple terms EEStaff1

...it is almost like a requirement if you are an engineer you have to be a big science fiction fan, yes, in this department especially - my integration would have been better if I was a Trekkie EESaff4 
A characteristic that had been identified in the study was the self-reliant, can-do, strength of character that seemed to be a quality present or developed by those who might be deemed successful engineers. Several staff made comments such as these, in relation to the personal outcomes for Electrical Engineering students:
What worries me is that they come out the other end of the electrical department quite demoralised and when I see students in other departments they come out more enthusiastic. EEStaff4 We seem to turn silk purses into sows ears instead of the other way round EEStaff2

A particular concern was for those female students from this discipline who, when questioned about their experiences through the degree, used comments such as these, which were illustrative rather than singular examples:
I no longer believe in myself
Questionnaire F6
I could never get passionate about engineering. I don't think anybody could.
Miriam

In contrast to the distinctive hegemonic masculinities within Civil and Electrical Engineering, disciplines such as Engineering Science and Chemical Engineering appeared to manifest a range of masculinities. Although Chemical and Materials Engineering had a predominantly long serving male staff, the reasonably high level of female participation over a number of years appeared to have led to an environment in which women were treated as individuals, rather than generalised as a group. From a student point of view the male staff were seen as rather bland and conservative:

Our lecturers have been there a long time - yeah, I can't think of many other ways of describing them - straight, boring and conservative - there seems to be a few more nippy ones starting

Karol

Again, Engineering Science was an anomaly. Staff were younger than in most other departments, and included two and later three female lecturers, with a higher than usual proportion of staff with backgrounds from outside engineering (such as applied mathematics or statistical backgrounds). Staff from this department taught in the cross-disciplinary Mathematical Modelling and Introductory Computing courses and therefore all students were exposed to them at first year level. "Hard driving achievers" and "really good problem solvers" were terms applied to the staff:

This department is pretty kind of uncompromising in terms of hard driving standards, there are a lot of A type males all trying to achieve and working very long hours ESciStaff2

but also images of athleticism, and friendly informality abounded:

M... is really cool .... she has a real give it a go attitude, she says funny things, not afraid to think "I
am so cool..."

There appeared to be a perception of elitism in terms of their mathematics ability, but students from this department never spoke of the discipline as "macho" and a very comfortable use of gender inclusive language, with very little crass or sexist joking was observed. The department had been a major supporter of affirmative action for women in engineering for close to twenty years.

The "heroes" of "real engineering" were associated with Design, in which male students were perceived as being advantaged. This attribute was particularly apparent in Mechanical Engineering which focussed not only on theoretical scientific knowledge, but also on the ability to use that knowledge in Design and problem solving. A very practical, "can do" 
attitude appeared to be valued, and although a background which included some "tinkering" experience was useful and helpful in recognising terminology and applying theory, it was recognised that the current student body did not all have that background:

Seems to be a sentimental longing for students who used to help Dad repair the car - we say students don't tinker any more but they do, they tinker with computers but it is not a mechanical type of tinkering. MechStaff3

The majority of the women encountered in Mechanical Engineering, both from the late 1990s and more recently, were lacking in the directly relevant "tinkering" experience that their male peers spoke of:

I found it very difficult as a girl from a single sex school not having any practical application of knowledge like motors and bearings. I think most boys at school get a definition of something and then a practical application of it.

Questionnaire F19

They were aware that lecturers made assumptions, as these comments illustrated:

I was not used to mechanical concepts and things but there were a lot of assumptions in the way we were taught... it was ... "things were obvious" or an example ...was something related to a car engine or something that you were expected to be familiar with and I was just getting lost... Chloe

Terminology and jargon which all males seem to attain at birth was not always easily grasped

Questionnaire F9

The "heroes" of Design courses and competitions were almost always male students, and although women students enjoyed design courses, the same level of commitment and passion was not as apparent from them as from their male peers.

In Electrical Engineering "practicality" was linked to familiarity with electronics and computers, rather than any hands-on exposure to cars, machinery or construction. Female students, even the highest academic achievers, almost unanimously perceived themselves as lacking, compared to their male peers, in computer and electronics skills and experience:

I think they (male students) are a little less frightened of the whole technological twiddling knobs, fiddling with the oscilloscope, building...

Melanie

... some of the guys in our class had little labs set up in their house whereas I wouldn't think of that as my hobby

Geetha,

By contrast, several of the male students interviewed had hobbies or interests that may have led them into electrical engineering, such as tinkering with electronics kits, theatre lighting and a passionate interest in computers.

Although, as stated in earlier chapters, Design was an essential and valued component in all of the degree courses, a reliance on prior practical knowledge or tinkering experience did not seem as essential in disciplines such as Engineering Science or Chemical Engineering, with the majority of courses new to all.

\section{Discussion}

Using even the small sample of the shared understandings provided in the previous two sections it becomes apparent that no one factor explained the persistence of sub-disciplinary participation rates. Rather, it was the combination of several, inter related factors which become even more complex when other dimensions such as the influence of teaching and 
learning practices, the availability and type of relationships within the group, and the level of acceptance of diversity or difference.

In the preceding section quite distinct hegemonic masculinities, using Connell's ${ }^{20}$ definition, were identified in the traditional New Zealand male model of masculinity found in Civil and Mechanical Engineering, and the technological obsession of Electrical Engineering. By contrast, the disciplines of both Chemical Engineering and Engineering Science evidenced "softer", less "macho", but still recognisably masculine, cultural norms, without any one form of masculinity appearing to be dominant.

In Figure 2 the traditional imagery of "blue for a boy and pink for a girl" has been used to symbolise these masculinities. Shades of blue indicate the different masculinities and purple (pink combined with blue) to suggest the more gender inclusive nature of Chemical and Materials Engineering and Engineering Science. The positioning of Engineering Science in this diagram reflects the strong interdisciplinary links it has formed outside engineering. Despite courses taught in common with other engineering disciplines such as Mechanical Engineering and its professional engineering accreditation, this discipline was perceived as located on the borderline of a "true" engineering discipline.

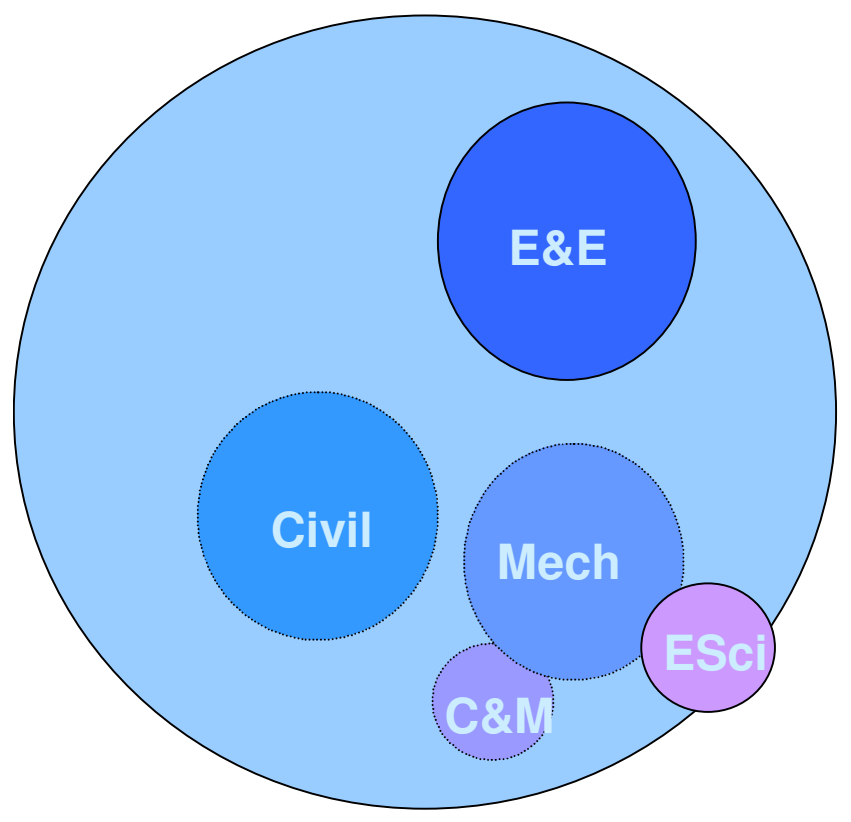

Figure 2 A symbolic representation of the masculinities of the Engineering Sub-disciplines

The level of integration of female students into these various disciplines appeared to be linked to the extent they, as women and as engineers, needed, and were prepared, to identify with these masculinities. This integration was both academic, requiring adaptation to the prevailing way of thinking and doing within the discipline, and social, requiring the support of task-oriented friendships. Even within the most masculine of disciplines, a supportive niche allowed the fulfilment of their academic and personal potential. Cobbin's 9 suggestion that women entered engineering leaving the traditions and culture intact, was largely confirmed in my study. The comfort and enjoyment of their educational experience reported by the majority of female students implied that adaptation and integration was accomplished 
with relative ease, but only in Engineering Science did the culture appear to have "opened up" to value and include women.

\title{
Conclusion
}

Whilst it is not suggested that female students consciously think in terms of culture when selecting their chosen discipline, the answer to the first question posed at the beginning of this paper - "Is it a self-fulfilling prophecy that engineering disciplines with more women develop cultures that attract more women?" - appears to be yes. The next question posed was "Can, and should, this pattern be disrupted?". For some of those who have been involved in female recruitment over a long period of time this question is more difficult and should perhaps be debated at length. If a culture is unwelcoming, it might be said to be almost unethical to advertise and attempt to recruit women without firm commitment and support to cultural change at both the academic and social levels.

Some of the findings from this study, and the "taster" provided in this paper will be unique to the institution, and perhaps even the country of origin, but statistical and anecdotal data suggest that many of the cultural features noted here are readily recognisable.

A change of culture is not a quick process, requiring not only a change in behaviors and practices, but enough exposure and reinforcement to those behaviors and practices to shift values and cultural norms and ultimately the unconsciously held beliefs and assumptions that are the essence of culture. It is hoped that the sharing of some of the results of this study of discipline specific cultures, will assist others in identifying not only the obdurate but also the malleable cultural features of engineering education within their institution or discipline, and enable the formulation of new approaches to women's participation in engineering education. There are no simple or complete answers but:

\author{
We shall not cease from exploration \\ And the end of all our exploring \\ Will be to arrive where we first started \\ And know the place for the first time
}

T.S.Eliot "Four Quartets"

\section{Bibliography}

1. McIlwee, J. and G. Robinson, Women in Engineering: Gender, Power and Workplace Culture. 1992, Albany, N.Y.: State University of New York Press.

2. Lewis, S., et al., Further explorations of masculinity and the culture of engineering. Australasian Journal of Engineering Education, 1998. 8(1): p. 59-78.

3. Godfrey, E. and L. Parker, How we do things round here: The gendered culture of an engineering institution, Paper Presented at Winds of Change: Women and the Culture of Universities. 1998: University of Technology Sydney.

4. Stonyer, H., Making engineering students -Making women: The discursive context of engineering education. International Journal of Engineering Education, 2002. 18(4): p. 392-399.

5. Tonso, K., Engineering gender- gendering engineering: A cultural model for belonging. Journal of Women and Minorities in Science and Engineering, 1999, 5: p. 365-405. 
6. IEAust, Changing the culture: Engineering education into the future. 1996, Institution of Engineers Australia: ACT.

7. Godfrey, E. A Theoretical Model of the Engineering Education Culture: A Tool for Change. Paper presented at the Annual Conference of the American Society for Engineering Education. 2003. Nashville, TE.

8. Women in Engineering and Related Fields - Diversity Analysis of Students earning Bachelor's degrees. Critical Issues Series: Dedicated Engineers. June, 2006 Accessed on 12 January, 2007 from http://www.dedicatedengineers.org/news_pubs/Critical_Issues_Women_6-06.pdf

9. Byrne, E., Women and science: The snark syndrome. 1993, London: The Falmer Press.

10. Cobbin, D., Womens participation in non-traditional fields of study at the undergraduate level of higher education 1989-1993. 1995, Canberra: Australian Government Publishing Service.

11. CuWaT, Changing the curriculum - changing the balance. 1998, Uni of Central Lancashire, UK / European Union "Leonardo da Vinci Project.

12. U.S. Dept. of Education's National Center for Education Statistics' (NCES) survey, “IPEDS Completions Survey - Degrees/Awards Conferred (NSF population of institutions)," with survey data obtained from the National Science Foundation's WebCASPAR database. Accessed on 12 January 2007 from http://www.dedicatedengineers.org/news_pubs/Critical_Issues_Women_6-06.pdf

13. Godfrey, E., The culture of Engineering education and its interaction with gender: A case study of a New Zealand university, Unpublished $\mathrm{PhD}$ dissertation,2003, Curtin University of Technology: Perth. Available at http://adt.curtin.edu.au/theses/available/adt-WCU20040105.130533/

14. Schein, E.H., Organisational culture and leadership. 2nd ed. 1992, San Francisco: Jossey-Bass.

15. Merriam, S.B., Case study research in education: A qualitative approach. 1988, San Francisco: JosseyBass.

16. Tonso., K.L., The impact of cultural norms on women. Journal of Engineering Education, 1996. 85(3): p. 217-225.

17. Hacker, S., Mathematization of engineering:Limits on women and the field, in Machine ex dea, J. Rothschild, Editor. 1983, Pergamon Press: USA. p. 38-58.

18. Baxter Magolda, M.B., Knowing and reasoning in college. 1992, San Francisco: Jossey-Bass.

19. Belenky, M.F.,Clinchy, B.M., Goldberger, N.R., \& Tarule, J.M., Women's Ways of knowing. 10th ed. 1997, New York: Basic Books.

20. Connell, R.W., Masculinities. 1995, Sydney: Allen \& Unwin.

21. Phillips, J., A man's country? The image of the Pakeha male. (Rev Ed) 1996, Auckland, NZ: Penguin Books. 